\title{
Social Disruptions and Work-Related Absenteeism: A Debilitating Effects of Low Back Pain Among Healthcare Workers
}

\author{
Aremu Abdulmujeeb Babatunde*1, Nwanna Uchechukwu Kevin², Ilori Oluwole ${ }^{3}$, Afolabi Kamaldeen Kolawole ${ }^{4}$ and \\ Salaam Mujeeb ${ }^{5}$ \\ ${ }^{1}$ Human Anatomy/Community Medicine Department, Habib Medical School, Faculty of Health Science-Islamic University, Uganda \\ ${ }^{2}$ Public Health Department, Victoria University, Uganda \\ ${ }^{3}$ Behavioural Science Department, Habib Medical School, Faculty of Health Science-Islamic University, Uganda \\ ${ }^{4}$ Public Health Department: Cavendish University Uganda \\ ${ }^{5}$ Department of Pathology, Habib Medical School, Faculty of Health Science-Islamic University, Uganda
}

Received: 温 July 26, 2018; Published: 眥 August 09, 2018

*Corresponding author: Aremu Abdulmujeeb Babatunde, Human Anatomy/Community Medicine Department, Habib Medical School, Faculty of Health Science-Islamic University, Uganda

\section{Abstract}

Introduction : Consequently low back pain to the government and other employers (Healthcare industry) include high cost of workers' compensation insurance to be paid to injured workers, recruitment or training costs and lost time This study sought to address the objectives : To determine if there is significant relationship between people suffering from low back pain and work related absenteeism and to determine if there is significant relationship between people suffering from low back pain and social disruptions.

Design: This was a qualitative and quantitative using questionnaire, interviews and focus groups discussion.

Setting and Participant: This study comprises of all healthcare workers present in Kibuli Muslim Hospital, Kibuli-Uganda

Methods: A cross-sectional survey was employed and a total number of 150 self-structured questionnaires were distributed among healthcare workers and this was used to determine the prevalence of low back pain and work-related absenteeism. Data was entered using Epi info soft-ware and analyzed using SPSS

Results: The study highlighted the debilitative effects of low back pain among the healthcare workers has affected their loss of working days and social disruptions (experiences of isolation, inability to pursue hobbies and leisure activities).

Conclusion: The findings from this study revealed the outcome that should be measured in studies that will be evaluating the treatment of excruciating effects low back pain among the healthcare workers and also a better understanding of appropriate intervention.

Keywords: Low Back Pain; Absenteeism; Healthcare Workers

\section{Introduction}

Low back pain (LBP) has been one of the most leading causes of disease burden across the developed and developing countries [1]. LBP is widespread and is the most disabling factor in the workplace [2]. With a rapid transition to industrial lifestyle, LBP imposes a significant economic burden on governments, particularly in terms of health system costs, lost working days, reduced productivity and increased disability $[3,4]$. A study conducted in Tunisia by Bejia I et al. [5]. showed that the lifetime prevalence of LBP was $57 \%$ and the annual prevalence was 50\% among all the hospital staff [5]. The consequence of low back pain to the government and other employers (Healthcare workers) include high cost of workers' compensation insurance to be paid to injured workers, recruitment or training costs and lost time [6]. It was also noted that majority of healthcare professionals have the risk of musculoskeletal system disorders.

The riskgroups of low back pain among healthcare professionals are physicians, dentists, nurses, physiotherapists, laboratory workers and caregivers [7]. Consequently, the replacement of injured staff can influence the stability, efficiency and quality of health care services. The social interruption that was as a result of low back pain cause participation restriction and inadequacy in fulfilling social or interpersonal relations to the sufferers. 
Individuals with low back pain have been found to have lost or decreased interactions in leisure activities; suffer from increased family stress and being a loss to their social group and community [8]. Bener in their findings showed that low back pain was found to seriously interfere with the interpersonal relationships between the majority of the sufferers and their relatives [9]. Ndhlovu, 2012 found that hospitals bear high cost in terms of working days lost in terms of compensation and treatments of the staff [10]. Due to paucity of information on absenteeism and social disruptions as results of work-related low back pain among healthcare workers most especially in African settings, hence the need for study like this.

\section{Objectives}

This study sought to address the following objectives: To determine if there is significant relationship between people suffering from low back pain and work related absenteeism and to determine if there is significant relationship between people suffering from low back pain and social disruptions among Healthcare workers in Kibuli Muslim Hospital Kibuli-Uganda.

\section{Methods}

The current study is a cross-sectional study; a self- administered questionnaire was adopted for collection of data among healthcare workers which is appropriate for describing the relationship of phenomenon at a point in time. The questionnaire was first piloted to test for the validity and reliability among 10 healthcare workers which showed no major modifications on the questionnaire. Data was collected from the healthcare workers after seeking approval from the management of Kibuli Muslim Hospital and Ethical Clearance from International Health Science University Research committee before the research was conducted. The questionnaire consists of the socio-demographic factors, age, gender, marital status, height, weight, BMI, smoking, alcohol consumption. The second section consist of occupational profile and activities and profession like, Doctor, Nurses, Pharmacy, Physiotherapy etc. and the activities like bending, lifting, standing and twisting. The third sections consist of LBP history which helps reveal its prevalence. Finally, the last section is on work setting and the effect of LBP on daily activities. The questionnaire was distributed among 140 healthcare workers in Kibuli Muslim hospital, Kampala Uganda.

\section{Data Analysis}

After the completion of data collections, the data was captured in spreadsheet using Epi-data version 3.1 for the data entering and coding, double data entering was done to ensure a data quality. Thereafter, data was exported from Epi-data to Statistical Package for the Social Sciences (SPSS) version 20.0 for data analysis. Descriptive statistics was employed to summarize the demographic data of the study sample. The demographic data was presented using frequency tables and also percentages and means. Chi square test was used to determine if there are any associations existing between low back pain and socio-demographic variables, occupational activities, lifestyle, health facilities variables. All tests in this study were done at the significance level of $\mathrm{P} \leq 0.05$ since they are both categorical variables.

\section{Results}

The results of the study were presented here as follows: The Table 1 above gives the significant summary of participant among the healthcare workers who took leave at work and the back pain prevalence among the health care workers. $31 \%(n=31)$ among the participant who took sick leave, and out of this 93.55\%( $n=29)$ of those who took sick leave have low back pain. The findings from the Chi- square test $\mathrm{X}^{2}=3.048 \mathrm{P}$ value $=0.08$ shows that there was high prevalence of law back pain among these who took sick leave but it was not significant at $\mathrm{P}$ value greater than 0.05 . The Table 2 below gives a significant summary of the healthcare workers that the low back pain has affected outside their working area/ leisure times informs of social disruptions. Out of $84 \%(n=84)$ of the participant who have low back pain, $72.62 \%(n=61)$ where affected in their leisure /other activities. The test result using Chi- square $\mathrm{X}^{2}=$ $20.839 \mathrm{P}$ value $=0.000$ revealed that a significant association exists between the leisure activities and low back pain among the healthcare workers, where the P value is 0.000 and is less than 0.05 Leisure /other activities and prevalence of low back pain among the healthcare workers

Table 1: Taking of a sick leave at work and prevalence of low back pain among the healthcare workers.

\begin{tabular}{|c|c|c|c|c|c|c|}
\hline & \multicolumn{2}{|c|}{$\begin{array}{c}\text { Have Ever } \\
\text { Experienced Low } \\
\text { Back Pain? }\end{array}$} & \multirow[t]{2}{*}{ Total } & \multirow[t]{2}{*}{$\begin{array}{c}\text { Chi } \\
\text { Square }\end{array}$} & \multirow[t]{2}{*}{ P-Value } \\
\hline & & Yes & No & & & \\
\hline \multirow{2}{*}{$\begin{array}{c}\text { Have You Ever } \\
\text { Taken A Leave } \\
\text { Because of the } \\
\text { Pain? }\end{array}$} & yes & 29 & 2 & 31 & 3.048 & 0.081 \\
\hline & no & 55 & 14 & 69 & & \\
\hline Total & 84 & 16 & 100 & & & \\
\hline
\end{tabular}

Table 2: Leisure/other activities and prevalence of low back pain among the healthcare workers.

\begin{tabular}{|c|c|c|c|c|c|c|}
\hline \multicolumn{2}{|c|}{} & \multicolumn{2}{|c|}{$\begin{array}{c}\text { Have Ever } \\
\text { Experienced } \\
\text { Low Back Pain? }\end{array}$} & \multirow{2}{*}{ Total } & $\begin{array}{c}\text { Chi } \\
\text { Square }\end{array}$ & P-value \\
\cline { 2 - 6 } & Yes & No & & & \\
\hline $\begin{array}{c}\text { Has the low back } \\
\text { pain affected } \\
\text { you outside your } \\
\text { work in terms of } \\
\text { daily activity? }\end{array}$ & yes & 61 & 2 & 63 & 20.839 & 0 \\
\hline Total & 23 & 14 & 37 & & \\
\hline Total & 84 & 16 & 100 & & \\
\hline
\end{tabular}

\section{Discussion}

Taking of leave at work because of the low back pain was found to be significantly associated with the occupation of the health care workers at $\mathrm{P}<0.05(\mathrm{p}=0.011$ and also the time spent during the occupational activities who were also found to be statistically not significant at $(\mathrm{P}=0.08)$. However, taking of leave at work was not found to be significant with development of low back pain among the participant. The findings here in this study were similar to a study done by Sikiru and Hanifa in Nigeria among Hospital staff to determine the risk factors of low back pain. Most of the workers who took leave have the symptoms of low back pain. Taking of leave from worker was also more common among the nursing staff and 
also high among the married participants. As at the time of this research the human resource unit of the hospital did not have data specific to absenteeism related to low back pain but had general data on leave of absence due to sickness. Therefore, the responses from the participants was the bases where the information on absenteeism was drawn. The social disruption which was presented in this study as experiences of isolation, inability to pursue hobbies and leisure activities was found to be significantly associated to the development of low back pain among the Healthcare workers. This was in line with the findings from Berner which shows that Individuals with low back pain have been found to have lost or decreased interactions in leisure activities; suffer from increased family stress and being a loss to their social group and community. Another study in Turkey by Aslan [10]. The relationship between performance based functional tests, fear avoidance behavior and depressive symptoms in older adults with low back pain based on their analysis [11].

\section{Conclusion}

It is pertinent to determine how low back pain is enhancing absenteeism and social disruption among healthcare workers. The findings from this study revealed the outcome that should be measured in studies that will be evaluating the treatment of excruciating low back pain among the health- care workers and also a better understanding of appropriate interventions. There is a need for establishment, implementation and monitoring of occupational health and safety interventions in the workplace to prevent LBP.

\section{Limitations}

This study did not take into consideration the cost implication of absenteeism among healthcare workers to individual and to the hospital. This study was narrowed down this two factors and some other risk factors were not considered.

\section{Acknowledgment}

We appreciate the support giving by the management and the staff of Kibuli Muslim Hospital, Kampala during the conduct of the study, the hospital Physiotherapist/research assistant Sulaiman Dungu was also helpful in the administration of the questionnaire.

\section{References}

1. Liebers F, Brendler C, Latza UB (2013) Age-and occupation-related differences in sick leave due to frequent musculoskeletal disorders. Low back pain and knee osteoarthritis. Undesgesundheitsblatt Gesundheitsforschung Gesundheitsschutz 56(3): 367-380.

2. Meucci RD, Fassa AG, Faria NM (2015) Prevalence of chronic low back pain: Systematic review. Rev Saude Publica p. 49.

3. Gouveia N, Rodrigues A, Eusébio M, Ramiro S, Machado P, et al. (2016) Prevalence and social burden of active chronic low back pain in the adult Portuguese population: results from a national survey. Rheumatol Int 36(2):183-197.

4. Bejia I, Younes M, Jamila HB, Khalfallah T, Ben Salem K, et al. (2005) Prevalence and factors associated to low back pain among hospital staff. Joint Bone Spine 72(3): 254-259.

5. Menzel NN, Lilley S, Robinson ME, Warms C (2006) Interventions to Reduce Back Pain in Rehabilitation Hospital Nursing Staff/Commentary. Rehabilitation Nursing 31(4): 138-147.

6. Tunç P (2008) Musculoskeletal disorders and factors affecting quality of life in health workers. Başkent University Institute of Health Sciences Physical Therapy and Rehabilitation Program Graduate Thesis Ankara p. 11.

7. Claiborne Nancy, Auerbach Charles, Lawrence Catherine, Mc Gowan Brenda, Lawson Hal, et al. (2014) Design Teams as an Organizational Intervention to Improve Job Satisfaction and Worker Turnover in Public Child Welfare. Journal of Family Strengths 14(1).

8. Bener A, El Rufaie OF, Kamran S, Georgievski AB, Farooq A, et al. (2006) Disability, depression and somatization in low back pain population. APLAR Journal of Rheumatology 9(3): 257-263.

9. Teboho Qhomane Mhlanga (2014) The Impact Of Musculoskeletal Disorders On Absenteeism In Hospital Workers In The Mangaung Metropolitan District.

10. Aslan Telci E, Yagci N, Can T, Cavlak U (2013) The impact of chronic low back pain on physical performance, fear avoidance beliefs, and depressive symptoms: A comparative study on Turkish elderly population. Pakistan Journal of Medical Sciences 29(2): 560-564.

11. David GC (2005) Ergonomic methods for assessing exposure to risk factors for work-related musculoskeletal disorders. Occup Med (Lond) 55(3): 190-199.
ISSN: 2574-1241

DOI: 10.26717/BJSTR.2018.07.001556

Aremu Abdulmujeeb Babatunde. Biomed J Sci \& Tech Res

CC (i) This work is licensed under Creative

Submission Link: https://biomedres.us/submit-manuscript.php

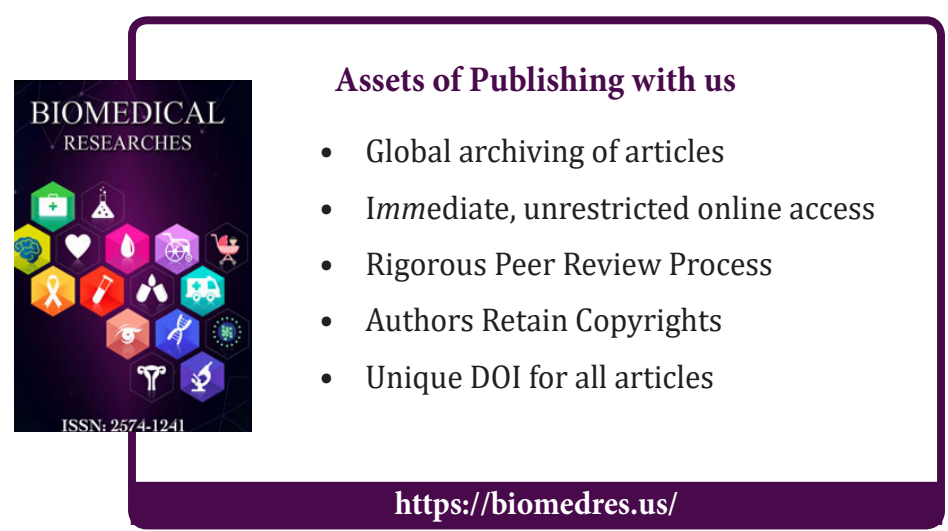

